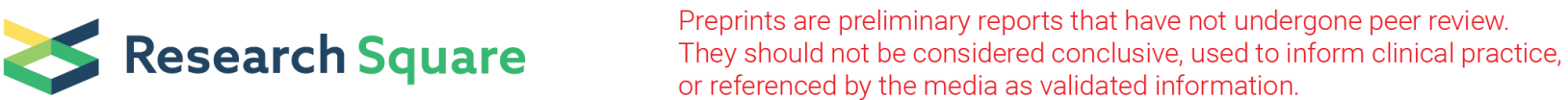 \\ Post-Pharmacy Exam - Are We Ready? - The Results of the Exam conducted in Poland on the Model of the UK
}

\section{Piotr Merks}

Collegium Medicum, Cardinal Stefan Wyszyński University

Urszula Religioni ( $\sim$ urszula.religioni@gmail.com )

Warsaw School of Economics

\section{Aleksandra Rutkowska}

University Hospitals Bristol and Weston NHS Foundation Trust

\section{Marvin Munzu}

Day-Lewis Pharmacy

\section{Edwin Panford-Quainoo}

Liverpool School of Tropical Medicine

\section{Agnieszka Barańska}

Medical University of Lublin

\section{Magdalena Waszyk-Nowaczyk \\ Poznan University of Medical Sciences \\ Jezrzy Krysiński \\ Collegium Medicum in Bydgoszcz}

\section{Research Article}

Keywords: pharmacist, education, pharmaceutical education, educational standards, Poland

Posted Date: September 27th, 2021

DOI: https://doi.org/10.21203/rs.3.rs-871778/v1

License: (c) (1) This work is licensed under a Creative Commons Attribution 4.0 International License. Read Full License 


\section{Abstract \\ Background.}

This article aims to present the results of the final exam in pharmacy among Polish pharmacy students. This exam was modeled on the British national exam supervised by the General Pharmaceutical Council.

\section{Methods.}

The exam was conducted in 3 cities in Poland, among a total of 175 final-year students. Taking the exam was voluntary and anonymous.

\section{Results.}

The results indicate that none of the Polish students achieved the $70 \%$ mark required to pass the Great Britain exam. Significant differences in test results were noticed between cities. Students achieved the best average exam result in Bydgoszcz (46.35\%), then in Warsaw (38.81\%) and Łódź (38.35\%)

\section{Conclusions.}

The pharmaceutical education system in Poland requires complete changes that will prepare future pharmacists for clinical work. Increasing the role of a pharmacist in health care requires raising the level of education and emphasizing the practical content of education.

\section{Background}

The pharmacist is one of the primary medical professionals in the healthcare sector. The main task of pharmacists is to improve patients' health and quality of life in the area of pharmacotherapy, regardless of whether they work in community or hospital pharmacies. The essential role of the pharmacist is to optimize patient treatment, including detection of adverse events and other drug errors. The significant influence of pharmacists on the increase in patients' adherence to the therapies is also emphasized. Furthermore, given the constantly growing health care spending, pharmacists' role in the optimization of therapy costs should be indicated [1-3].

The World Health Organization (WHO) and other organizations such as the American Society of HealthSystem Pharmacists (AHAP) emphasize that pharmacists are the health professionals most accessible to patients [4-5]. Therefore, they should be involved in patient care. The role of a pharmacist in different countries, including within Europe, varies significantly [6-7]. Many of these differences are due to curricula, including soft skills learning through pharmaceutical education. 
This article aims to compile the programs and standards of teaching the pharmacist profession in Poland and the United Kingdom (UK), including the final examination results, designed in Poland, similar to the pre-registration exam conducted at the end of pharmaceutical studies in the UK. The results of these considerations may be used to define new directions for pharmacists' education in Poland, including the development of recommendations and standards for teaching this profession in Poland.

\section{Pharmacy education in Poland}

In Poland, pharmaceutical studies are part of education in the field of medical sciences, health sciences, and physical education sciences. Studies last no shorter than 11 semesters, ending with the statutory work placement of 6 months. Additionally, after the 3rd and 4th year of studies, students complete one month of professional practice during the summer holidays [8-9]. The number of hours of classes and internships will be at least 5,300. The education standards of future pharmacists in Poland combine general and detailed learning outcomes, including knowledge in pharmaceutical, medical, biological, chemical, and social sciences. The pharmacy students in Poland obtain thorough knowledge about drugs and substances used in their production, pharmaceutical technology, metabolism, and effects of drugs, as well as the correct use of medicinal products. Students learn the methods and techniques of researching medicinal products in terms of chemical, pharmacological and toxicological properties. They gain knowledge of the basics of pharmaceutical law and management in pharmacy, including the principles of ethics and deontology [9].

Polish legal acts indicate that a graduate of pharmacy studies is required to achieve competence in the preparation, manufacture and quality assessment of medicinal products, providing reliable and objective information on the medicinal products and medical devices. A pharmacy graduate should understand the principles of pharmacotherapy rationalization, as well as skillfully conduct the research on both substances and medicinal products. General effects in the process of educating pharmacists in Poland in terms of knowledge and skills also take into account social competences by preparing future pharmacists to work in community pharmacies, hospital pharmacies, pharmaceutical wholesalers, the pharmaceutical industry, pharmaceutical inspection as well as other offices and institutions, both state and local, operating in the field of pharmacy and healthcare [9].

\section{Pharmacy education in the UK}

The education of pharmacists in the UK is regulated by an independent body of the General Pharmaceutical Council (GPhC). GPhC aims to protect and promote the health, safety, and well-being of people, especially those who need the services of pharmacists. Its main tasks include setting the requirements for practicing the profession, approving pharmacists and pharmacy technicians' qualifications, and keeping a register of pharmacists, pharmacy technicians, and pharmacies [10].

The General Pharmaceutical Council accredits universities educating students in pharmacy, ensuring pharmacists' quality of education. The Master of Pharmacy (MPharm) studies in Great Britain last four years [10]. Students are obliged to take at least 3,000 hours of classes directly related to pharmaceutical 
subjects during their studies, especially in relation to clinical practice. During their studies, students gain, amongst others, knowledge about the effects of drugs, the functioning of the human body, and broad universal competencies, including problem-solving, clinical decision-making, effective communication, numerical data analysis [10]. Students preparing to practice as pharmacists in the United Kingdom gain practical skills from the first year of study. They are exposed to working with the patients during which students also have the possibility of practical problem-solving and pharmaceutical care planning, resulting from the educational standards set by the GPhC.

After graduation from their respective Universities, future pharmacists perform a 12-month obligatory internship in a community pharmacy, hospital pharmacy, and the industry (or combining different types of practices). Completing the training is associated with taking the independent state examination conducted by the Royal Pharmaceutical Society, and obtaining a positive grade for this examination enables the use of the "pharmacist" title.

\section{Methods}

Based on the final exam after pharmaceutical studies in the UK, accredited by the General Pharmaceutical Council, we prepared the exam in Polish for Polish pharmacy students. The exam consisted of 45 test questions and 4 calculation questions, to be calculated without using a calculator. The test was divided into five different education modules, which had different forms of questions:

- Part I (13 questions) - simple completion answers;

- Part II (11 questions) - the best answer to the given question (multiple completion answers);

- Part III (12 questions) - the question of choosing the best most appropriate classification answers;

- Part IV (9 questions) - true / false (statement questions);

- Part V (4 questions) - calculation questions.

Sample questions are included in the attachment. The exam is passed when the student obtains a minimum of $70 \%$ of the points.

Students had 60 minutes to complete the test, and participation in the test was anonymous. The exam was conducted at Polish universities educating in the field of pharmacy in 2018. It was attended by fifthyear pharmacy students (volunteers) from universities in the following cities: Bydgoszcz 77 people (92.8\% of all students), Warsaw 55 people (38.2\%), and Łódź 43 people (39.1\%). A total of 175 people took the exam.

\section{Results}

The best average exam result was achieved by students from Bydgoszcz (46.35\%), then from Warsaw (38.81\%) and Łódź (38.35\%) (Table 1). 
Table 1

Average exam results in particular cities

\begin{tabular}{|lllllll|}
\hline & Part I & Part II & Part III & Part IV & Part V & Overall \\
\hline Warsaw & $49,51 \%$ & $37,69 \%$ & $41,52 \%$ & $25,66 \%$ & $28,64 \%$ & $38.81 \%$ \\
\hline Bydgoszcz & $62,44 \%$ & $28,22 \%$ & $48,16 \%$ & $30,16 \%$ & $74,35 \%$ & $46.35 \%$ \\
\hline Łódź & $43,83 \%$ & $38,05 \%$ & $38,37 \%$ & $33,85 \%$ & $31,40 \%$ & $38.35 \%$ \\
\hline
\end{tabular}

In order to evaluate the obtained results, the Shapiro-Wilk test was performed for students from each city (Table 2), which showed that for the significance level $p<0.05$ the critical values are greater than the calculated value, therefore the results are statistically significant.

Table 2

Shapiro-Wilk test results

\begin{tabular}{|llll|}
\hline & Warsaw & Bydgoszcz & Łódź \\
\hline p-value & 0.8484 & 0.1353 & 0.0599 \\
\hline Critical values for the probability level of $\mathbf{p}<0.05$ & 0.951 & 0.959 & 0.943 \\
\hline
\end{tabular}

A one-way ANOVA was then performed, which showed significant differences in the results between the groups: $p=0.000003(p<0.05)$. However, using the Fischer NIR test $(a=0.05)$, significant differences were identified between the results from Bydgoszcz and Warsaw and between Bydgoszcz and Łódź. The differences in the results between Warsaw and Łódź are not statistically significant (Table 3).

Table 3

Fischer NIR test results

\begin{tabular}{|llll|}
\hline & Warsaw & Bydgoszcz & Łódź \\
\hline Warsaw & - & 0.000010 & 0.959335 \\
\hline Bydgoszcz & 0.000010 & - & 0.000049 \\
\hline Łódź & 0.959335 & 0.000049 & - \\
\hline
\end{tabular}

The minimum and maximum results obtained on the test by students in individual cities are as follows: Warsaw: minimum value 12.2\%, maximum 65.3\%; Bydgoszcz: minimum value $20.4 \%$, max. $65.3 \%$; Łódź: 
minimum value $24.5 \%$, maximum $53.1 \%$. The above results indicate that none of the students taking the exam reached the $70 \%$ threshold for passing the test.

\section{Discussion}

Pharmacists are an integral part of health care systems [11-13]. They have the experience to detect, resolve, and prevent drug-related problems [14-15]. In many countries, such as the United Kingdom, pharmacists are involved in the interdisciplinary Primary Care Teams (PCT). They directly take care of the patient through activities such as participating in drug management and drug counselling, identifying undesirable or incorrect drugs, and managing chronic diseases [16]. These activities directly impact the improvement of health effects and the quality of life of patients [17].

Highly developed pharmaceutical education, which begins during studies, is a prerequisite for pharmacists' full and beneficial involvement in patient care. Despite the fact that both Poland and Great Britain signed the Bologna Declaration's assumptions, the teaching models in the discussed countries are significantly different. In the UK education programs, the clinical aspect of the classes is emphasized, which is the basis for practical preparation for broadly understanding of pharmaceutical care. Internships taking place from the first years of study, teach future pharmacists to cooperate with representatives of various medical professions, including doctors. This situation can significantly influence the current practice where decisions to treat the patient are discussed between doctors and pharmacists.

The role of the pharmacist in the United Kingdom is crucial [18]. While pharmacists in the UK are PCT members and take direct care of patients, in Poland, pharmacists are still perceived mainly as drug sellers.

The UK education system is widely regulated and independently supervised, including the state final examination. Notably, the state exam may have a maximum of 3 attempts. In the event of a triple failure on the test, students may not be allowed to work as pharmacist. The results indicating that none of the surveyed graduates of Polish universities obtained the required number of points emphasize the relatively low level of pharmacy education. Data obtained from the General Pharmaceutical Council show that in 2019 , the average pass rate in the United Kingdom is $72.33 \%$.

This will be a good point to also outline the pharmacy education system in Poland to compare and contrast the sections above. For this reason, it is necessary to develop a new model of education in Poland, based on the International Pharmaceutical Federation (FIP) guidelines and competency-based pharmacy education (CBPE) [19]. In order to assess the knowledge and competencies of future pharmacists, it is recommended to introduce a final exam at Polish universities, which would be supervised by an independent organization. The real threat to these activities may turn out to be a noticeable downward trend in the number of new pharmacists, which already amounts to 1.85 pharmacists per pharmacy and is much lower than the number of pharmacists per pharmacy in other OECD countries (2.40) [20]. 


\section{Conclusions}

The pharmaceutical education system in Poland requires complete changes. However, these modifications seem necessary to increase the pharmacist's role in the health care system and ensure the complete safety of patients. Although pharmacists are often overlooked in setting primary health goals, and their role in promoting health in many countries is still low, it should be noted that pharmacists are the medical profession most frequently visited by patients. Thus, great emphasis should be placed on educating pharmacists who can actively support patients' health in the area of pharmacotherapy, being also health educators.

\section{List Of Abbreviations}

AHAP - American Society of Health-System Pharmacists

CBPE - competency-based pharmacy education

FIP - International Pharmaceutical Federation

GPhC - General Pharmaceutical Council

MPharm - Master of Pharmacy

OECD - Organisation for Economic Co-operation and Developmen

PCT - Primary Care Teams

UK - United Kingdom

WHO - World Health Organization

\section{Declarations}

\section{Ethics approval and consent to participate}

The local ethics committee ruled that no formal ethics approval was required for that study. We confirm that all methods in the study were carried out in accordance with relevant guidelines and regulations. We confirm that informed consent was obtained from all subjects.

\section{Consent for publication}

Not applicable.

\section{Availability of data and materials}

All data are available from the corresponding author. 


\section{Competing interests}

None declared.

\section{Funding}

None.

\section{Authors' contributions}

Conceptualization: PM, UR; Methodology: PM; Formal Analysis: UR; Writing - Original Draft Preparation: UR; Writing - Review \& Editing: AR, PM, MM, AB, JK, MWN, EP-Q and UR; Visualization UR; Supervision: PM, EP-Q. All authors have read and approved the manuscript.

\section{Acknowledgements}

None.

\section{References}

1. Dalton K, Byrne S. Role of the pharmacist in reducing healthcare costs: current insights. Integr Pharm Res Pract. 2017;6:37-46.

2. Kokane JV, Avhad PS. Role of Pharmacist in Health Care System. The Journal of Community Health Management 2016;3(1):37-40.

3. Blouin RA, Adams ML. The Role of the Pharmacist in Health Care. North Carolina Medical Journal May 2017;78 (3): 165-167.

4. World Health Organization. Everybody's business - strengthening health systems to improve health outcomes: WHO's framework for action. Geneva: World Health Organization; 2007.

5. American Society of Health-System Pharmacists. ASHP statement on the role of health-system pharmacists in public health. Am J Health-Syst Pharm. 2008; 65:462-467.

6. Świeczkowski D, Merks P, Cwalina N, Jaguszewski MJ. Development of Pharmacy Practice in European Countries-The Polish Perspective. Pharmacy (Basel). 2017 Aug 2;5(3):43.

7. Azhar S, Ibrahim MIM. Quality of Pharmacy Health Services in: Social and Administrative Aspects of Pharmacy in Low- and Middle-Income Countries. Present Challenges and Future Solutions (Ibrahim MIM ed.). London: Elsevier; 2018, pp 281-294.

8. The Act of July 20, 2018 - Law on Higher Education and Science (Journal of Laws 2018, item 1668).

9. Regulation of the Minister of Science and Higher Education of 26 July 2019 on training standards for the profession of a doctor, dentist, pharmacist, nurse, midwife, laboratory diagnostician, physiotherapist and paramedic (Journal of Laws 2019, item 1573).

10. General Pharmaceutical Council. Future pharmacists Standards for the initial education and training of pharmacists. London, May 2011. 
11. Tsuyuki RT, Beahm NP, Okada H, Al Hamarneh YN. Pharmacists as accessible primary health care providers: Review of the evidence. Can Pharm J (Ott). 2018;151(1):4-5.

12. Raiche T, Pammett R, Dattani S. Community pharmacists' evolving role in Canadian primary health care: a vision of harmonization in a patchwork system. Pharm Pract (Granada). 2020;18(4):2171.

13. Samir Abdin M, Grenier-Gosselin L, Guénette L. Impact of pharmacists' interventions on the pharmacotherapy of patients with complex needs monitored in multidisciplinary primary care teams. Int J Pharm Pract. 2020 Feb;28(1):75-83.

14. Guénette L, Maheu A, Vanier MC, Dugré N, Rouleau L, Lalonde L. Pharmacists practising in family medicine groups: What are their activities and needs? J Clin Pharm Ther. 2020 Feb;45(1):105-114.

15. Shamim S, Sharib SM, Malhi SM. Adverse drug reactions (ADRS) reporting: awareness and reasons of under-reporting among health care professionals, a challenge for pharmacists. SpringerPlus 2016;5:1778.

16. Khaira M, Mathers A, Benny Gerard N, Dolovich L. The Evolving Role and Impact of Integrating Pharmacists into Primary Care Teams: Experience from Ontario, Canada. Pharmacy (Basel). 2020;8(4):234.

17. Hayhoe B, Cespedes JA, Foley K, Majeed A, Ruzangi J, Greenfield G. Impact of integrating pharmacists into primary care teams on health systems indicators: a systematic review. $\mathrm{Br} \mathrm{J}$ Gen Pract. 2019 Sep 26;69(687):e665-e674.

18. Benson H, Lucas C, Benrimoj SI, Williams KA. The development of a role description and competency map for pharmacists in an interprofessional care setting. Int J Clin Pharm. 2019 Apr;41(2):391-407.

19. Koster A, Schalekamp T, Meijerman I. Implementation of Competency-Based Pharmacy Education (CBPE). Pharmacy (Basel). 2017 Feb 21;5(1):10.

20. Supreme Pharmaceutical Chamber. Report on the Personnel Situation of Pharmacists for Poland. Available at: http://www.mpz.mz.gov.pl/wpcontent/uploads/sites/4/2018/06/raport_farmaceuci.pdf Accessed 22 December 2021.

\section{Supplementary Files}

This is a list of supplementary files associated with this preprint. Click to download.

- Attachment.docx 